\title{
EDITORIAL
}

\section{INVESTIGACIÓN HISTÓRICA E IDENTIDAD PROFESIONAL}

\author{
HISTORICAL RESEARCH AND PROFESSIONAL IDENTITY
}

\author{
Dra. Julia Huaiquian Silva \\ Departamento de Enfermería, Universidad de Concepción, Chile.
}

\begin{abstract}
Según afirma Arostegui (1), historia "es la cualidad temporal que tiene todo lo $\checkmark$ que existe y también, en consecuencia, su manifestación empírica -es decir que puede ser observada- de tal temporalidad". La memoria por su parte es una dimensión de la historia que legitima, suministra y cohesiona la identidad de un grupo al otorgarle un sentido. Como reconstrucción del pasado, la memoria no es fiel con todos los elementos de la realidad porque siempre se reproduce seleccionando. Cada pueblo tiene su memoria. La memoria colectiva es una idea simbólica representativa que se forja en el conjunto de tradiciones (rituales, mitos, creencias) que poseen los integrantes del grupo o cultura y que determina su adscripción al grupo (2).
\end{abstract}

La historia es un saber que debe constituirse como disciplina crítica que desmonta y desvela mitos y mistificaciones. Es función de la historia construir y administrar la memoria de cada sociedad, grupo o cultura. Función que es opuesta a la memoria, ya que la historia como saber social es una empresa crítica, destructora de identidades y de tradiciones, si se utiliza como análisis de los procesos sociales y no como su justificación. Esto siempre y cuando se quiera utilizar como una conciencia ciudadana que abra nuevos horizontes al futuro y no se quede anclada a los mitos del pasado (2).

Diversos historiadores de enfermería (3-5) coinciden en que el fenómeno de estudio de la disciplina de enfermería es un conjunto de procesos interrelacionados y dependientes de la evolución social en que están inmersos, por esta razón al indagar sobre la identidad profesional se debe partir de la premisa de que ningún dato actual podrá reemplazar el conocimiento histórico.

La historia de enfermería proporciona un sentido de patrimonio e identidad profesional y la investigación histórica amplía las bases del conocimiento y pro- 
mueve la comprensión de los orígenes sociales e intelectuales de enfermería incluida la epistemología (6).

Según comenta Siles (7) para que se produzca un paso libre al resultado del actual proceso de construcción de la historia de enfermería se deben deconstruir los clichés que obstruyen la transición entre una enfermería desprovista de historia a un grupo disciplinar que se ha aplicado por fin a la creación y gestión de su memoria histórica; es decir facilitar el cambio desde las coordenadas propias del ámbito doméstico a los campos enmarcados en los límites de la ciencia y profesionalidad.

Finalmente Colliere (8), destacada pensadora de enfermería, recomienda que para poder encontrar el sentido original de los cuidados enfermeros "hay que preguntar y comprender cuál es el origen, de los cuidados, de la profesión y de la enfermería. Por esto hay que seguir su rastro y preguntarse cuáles son sus connotaciones".

\section{REFERENCIAS}

1. Arostegui J. La investigación histórica: teoría y método. Barcelona. Crítica; 2001.

2. Pérez JS. Memoria y poder. La historia como empresa crítica. En: Mainer J, editor. Pensar críticamente la educación escolar, perspectivas y controversias historiográficas. España: Universidad de Zaragoza; 2008. p. 15-49.

3. Hernández Conesa JM. Historia de la enfermería. Un análisis histórico de los cuidados de enfermería. Madrid: McGraw-Hill; 1995.

4. Siles J. Historia cultural de la enfermería: reflexión epistemológica y metodológica. Avances en enfermería. 2010; XXVIII (número especial), 120-128.

5. Velandia AL. Historia de la enfermería en Colombia. Bogotá. Universidad Nacional de Colombia; 1995. p. 200.

6. Keeling A. Position paper on history in curriculum: preparing nurses for the 21st century [Internet]. Colorado: American Association for the History of Nursing, Inc; 1995 [citado 2 junio 2011]. Disponible en http://www.aahn.org/ position.html

7. Siles J. La construcción social de la historia de la enfermería. Index de enfermería. 2004; (47): 7-10.

8. Colliere M. Encontrar el sentido original de los cuidados enfermeros. Rev Enferm. 1999; 22 (1): 27-31. 